\title{
ABM Clinical Protocol \#31: Radiology and Nuclear Medicine Studies in Lactating Women
}

\author{
Katrina B. Mitchell, ${ }^{1}$ Margaret M. Fleming, ${ }^{2}$ Philip O. Anderson, ${ }^{3}$ Jamie G. Giesbrandt, ${ }^{4}$ \\ and the Academy of Breastfeeding Medicine
}

\begin{abstract}
\section{Introduction}

B REASTFEEDING WOMEN MAY be required to undergo diagnostic imaging and/or nuclear medicine procedures at any point during lactation. Many women report being incorrectly instructed to discard ("pump and dump") their breast milk or stop breastfeeding after procedures. We seek to provide guidelines and recommendations regarding the safety of common imaging and nuclear medicine procedures performed during lactation. Although the vast majority of circumstances do not require interruption of breastfeeding, certain exceptions do exist and will be reviewed. A summary of recommendations is provided in Table 1 .

It should be noted that breastfeeding mothers involved in the care of patients undergoing nuclear medicine procedures and/or imaging studies and procedures should take standard precautions. However, due to the fact that these health care workers are not directly ingesting, inhaling, or receiving intravenous radiopharmaceuticals and/or contrast, no interruption in breastfeeding is required. Should a mother have an unexpected exposure, the institutional Radiology Safety Officer (RSO) should be contacted. Other sources for recommendations regarding unintended health care exposures include MotherToBaby.org and Infantrisk.com
\end{abstract}

A central goal of the Academy of Breastfeeding Medicine is the development of clinical protocols for managing common medical problems that may impact breastfeeding success. These protocols serve only as guidelines for the care of breastfeeding mothers and infants and do not delineate an exclusive course of treatment or serve as standards of medical care. Variations in treatment may be appropriate according to the needs of an individual patient.

\section{Recommendations}

\section{Breast imaging}

Several organizations, including the American College of Radiology (ACR), have made recommendations regarding breast imaging in pregnant and lactating women. ${ }^{1-11}$
Screening. The ACR states that initiation or continuation of screening mammography should be considered dependent on the patient's individual risk and expected duration of lactation. This includes average risk women of age $\geq 40$ years as well as some intermediate- to high-risk women of age $<40$ years.

There is no contraindication to obtaining a mammogram during lactation. Nursing or expressing milk before mammography is recommended to decrease parenchymal density, thereby improving the sensitivity of mammography. Ultrasound may also be used as a supplemental screening modality in conjunction with mammography. The physiologic increased vascularity caused by lactation results in marked increase in background parenchymal enhancement of the breast on magnetic resonance imaging (MRI). For highrisk women breastfeeding for short periods of time, MRI should be performed 3 months after cessation of lactation. For high-risk women who plan to breastfeed for longer periods of time, MRI may be considered in addition to mammography for screening.

Diagnostic. Diagnostic breast imaging during lactation is the same as that for nonlactating women. For diagnostic evaluation of an area of palpable concern or persistent bloody nipple discharge, ultrasound is often the initial imaging modality. If ultrasound is either negative or demonstrates suspicious findings, additional imaging with mammography may be indicated.

\section{Noncontrast enhanced radiographic imaging}

The radiation associated with image acquisition in radiography has no effect on the breast milk itself. This includes plain

\footnotetext{
${ }^{1}$ Presbyterian Healthcare Services-MD Anderson Cancer Network, Albuquerque, New Mexico.

${ }^{2}$ Emory University School of Medicine, Atlanta, Georgia.

${ }^{3}$ Division of Clinical Pharmacy, Skaggs School of Pharmacy and Pharmaceutical Sciences, University of California, San Diego, La Jolla, California.

${ }^{4}$ X-Ray Associates of New Mexico, Albuquerque, New Mexico.
} 
Table 1. Common Nuclear Medicine Imaging Agents and Recommendations for Breastfeeding

\begin{tabular}{|c|c|}
\hline Imaging agent & Breastfeeding interruption \\
\hline Noncontrast radiographs & No \\
\hline Nonvascular administration of iodinated contrast & No \\
\hline CT with iodinated intravenous contrast & No \\
\hline MRI with gadolinium-based intravenous contrast & No \\
\hline \multicolumn{2}{|l|}{ Nuclear medicine imaging } \\
\hline PET & No \\
\hline Bone scan & No \\
\hline \multicolumn{2}{|l|}{ Thyroid imaging } \\
\hline $\mathrm{I}-131$ & Cessation for this infant \\
\hline $\mathrm{I}-123$ & Recommendations vary, up to 3 weeks \\
\hline Technetium-99m pertechnetate & Up to 24 hours, depending on dose \\
\hline \multicolumn{2}{|l|}{ Renal imaging } \\
\hline Tc-99m DTPA & $\mathrm{No}^{\mathrm{a}}$ \\
\hline Tc-99m MAG3 & $\mathrm{No}^{\mathrm{a}}$ \\
\hline Tc-99m DMSA & $\mathrm{No}^{\mathrm{a}}$ \\
\hline Tc-99m glucoheptonate & $\mathrm{No}^{\mathrm{a}}$ \\
\hline \multicolumn{2}{|l|}{ Cardiac imaging } \\
\hline Tc-99m Sestamibi & $\mathrm{No}^{\mathrm{a}}$ \\
\hline Tc-99m Tetrofosmin & $\mathrm{No}^{\mathrm{a}}$ \\
\hline \multicolumn{2}{|l|}{ MUGA } \\
\hline Tc-99m RBCs in vitro & $\mathrm{No}^{\mathrm{a}}$ \\
\hline Tc-99m RBCs in vivo & Up to 12 hours, depending on dose \\
\hline \multicolumn{2}{|l|}{ VQ scan } \\
\hline Tc-99m MAA & 12 hours \\
\hline \multicolumn{2}{|l|}{ Breast imaging } \\
\hline Screening or diagnostic mammography & No \\
\hline Ultrasound & No \\
\hline MRI with gadolinium-based intravenous contrast & No \\
\hline
\end{tabular}

${ }^{a}$ The International Atomic Energy Administration recommends withholding breastfeeding for 4 hours or one feeding to account for any external radiation and free Tc99m pertechnetate in the product.

CT, computed tomography; MRI, magnetic resonance imaging; MUGA, multigated acquisition scan; Tc-99m MAA, technetium-99m macroaggregated albumin; PET, positron emission tomography; Tc-99m MAG3, technetium-99m mertiatide; Tc-99m DMSA, technetium99m succimer; VQ, ventilation-perfusion.

film radiography, fluoroscopy, mammography, and computed tomography (CT). Do not interrupt breastfeeding for any of these procedures.

\section{Nonvascular administration of iodinated contrast}

When iodinated contrast is administered through nonvascular routes, systemic absorption of these contrast agents is low and has few known adverse reactions. However, there are reports of anaphylactoid-like reactions with these agents, so some degree of systemic absorption can occur. With enteral administration (e.g., oral or rectal), excretion is through the fecal route and is dependent on bowel transit time. Intracavity (e.g., hysterosalpingography) or intravesical (e.g., cystography) administration may result in small amounts being absorbed and excreted through the kidneys; however, most contrast drains from the cavity after the conclusion of the procedure. There is a paucity of information regarding concentration of nonvascularly administered contrast agents in breast milk and guidelines on breastfeeding after such procedures are not available. ${ }^{12,13}$ However, based on very low systemic absorption rates and known low excretion of intravenously administered contrast into breast milk, we do not recommend routine interruption of breastfeeding for these types of procedures.

\section{CT with iodinated intravenous contrast}

CT uses a form of intravenous contrast containing highly bound iodine that helps visualize vascular structures and organs. Less than $1 \%$ of the administered maternal dose is excreted into the breast milk, ${ }^{14,15}$ and $<1 \%$ of the contrast ingested by the child is absorbed by the gastrointestinal (GI) tract. ${ }^{16}$ Therefore, the systemic dose to the child is $<0.01 \%$ of the intravenous dose given to the mother. The ACR states in its published manual on contrast media that it is safe for the mother to continue breastfeeding after the administration of intravenous iodinated contrast. ${ }^{12}$ This recommendation is based on multiple studies that have demonstrated the safety and efficacy of iodinated contrast in the breastfeeding patient. ${ }^{14-18}$ The taste of the breast milk may be altered slightly after administration of intravenous iodinated contrast, but it is not harmful to the breastfeeding child.

\section{MRI with gadolinium-based intravenous contrast}

Gadolinium is a heavy metal incorporated into intravenous contrast agents to enhance vascular structures and organs during MRI. Less than $0.04 \%$ of the administered maternal dose is excreted into the breast milk, ${ }^{17,19,20}$ and $<1 \%$ of the contrast ingested by the child is absorbed from the 
GI tract. ${ }^{20,21}$ Therefore, the systemic dosage to the child is $<0.0004 \%$ of the intravenous dose given to the mother. The ACR states in its published manual on contrast media that it is safe for the mother to continue breastfeeding after the administration of intravenous gadolinium-based contrast. ${ }^{12}$ This recommendation is based on numerous studies that have shown the safety of gadolinium-based contrast in the breastfeeding patient. ${ }^{15-21}$ The taste of the breast milk may be altered slightly after intravenous gadolinium-based contrast, but it is not harmful to the breastfeeding child.

\section{Nuclear medicine imaging}

Nuclear medicine imaging involves the use of radioactive materials called radionuclides or radiopharmaceuticals to produce functional imaging of the body. Depending on the study, these materials may be inhaled, injected intravenously, or ingested orally. Images are then obtained to document sites of accumulation within the body.

When advising the breastfeeding patient, consideration must be given to the fact that a child may be exposed to radiation through two routes. The most common route of exposure is radioactivity within the ingested milk itself. The other possible route to consider is external exposure while in proximity to the mother. This second situation occurs when metabolically active lactating breast tissue concentrates the administered radioactivity. This second route of exposure is only a concern with fludeoxyglucose-F18 (FDG), the agent used for positron emission tomography (PET). The other agents discussed do not accumulate within active breast tissue. ${ }^{22}$ The risks involved with specific agents are discussed hereunder.

Estimated radiation doses to the child from ingested radioactivity have been reported for the most common radiopharmaceuticals used in diagnostic nuclear medicine. As a general rule, no interruption of breastfeeding is required for radiation doses $<100$ mrem $(1 \mathrm{mSV}){ }^{23}$ Both the Nuclear Regulatory Commission (NRC) and International Commission on Radiological Protection (ICRP) have published guidelines for the most commonly used radiopharmaceuticals. Note that recommendations for some agents differ between the NRC and ICRP, and the International Atomic Energy Agency (IAEA) recommends an interruption of breastfeeding for four hours or one feeding to account for any external radiation and free $\mathrm{Tc} 99 \mathrm{~m}$ pertechnetate in the product. ${ }^{22-31}$

Positron emission tomography. PET is one of the most commonly ordered nuclear medicine studies and is often used in cancer diagnosis and staging. FDG is chemically similar to glucose, but with the positron-emitting radionuclide fluorine18 substituted on the molecule allowing identification of metabolically active lesions in the body.

FDG is not excreted into breast milk. Contact between the mother and child, however, should be limited for 12 hours after the injection of FDG due to radioactivity concentrated within the breast tissue itself. Milk can be expressed and safely given to the child during this time. The milk does not need to be discarded.

Bone scan. Bone scans can be used to detect osseous metastatic disease and most commonly use technetium 99mmedronate (Tc-99m MDP). Very little Tc-99m MDP is excreted into breast milk. No interruption in breastfeeding is required.
Thyroid imaging. There are three radionuclides used in nuclear thyroid imaging: 1-131, I-123, and pertechnetate Tc $99 \mathrm{~m}$. I-131 is most commonly used for the treatment of thyroid cancer or Graves' disease. Although it is sometimes used to assess metastases in the setting of thyroid cancer, I-131 is generally not used for routine thyroid imaging due to its high principle gamma energy $(364 \mathrm{keV})$, high beta emission (resulting in large dose to the thyroid), and long half-life (8.04 days). Use of I-131 requires complete cessation of breastfeeding this child. It is recommended that breastfeeding is stopped at least 4 weeks before receiving a therapeutic dose of I-131. This reduces radiation dose to the breast and reduces the risk of contaminating clothing with milk leakage of radioactive iodine. ${ }^{32}$

I-123 and pertechnetate Tc 99m are the preferred radionuclides for routine thyroid imaging. I-123 results in a lower dose to the thyroid than I-131 and also has a shorter halflife than I-131 (13 hours versus 8 days). Recommendations with regard to breastfeeding after I-123 administration vary. Some sources cite no interruption required, whereas others recommend up to 3 weeks interruption. We recommend discussion with your local nuclear medicine physician regarding approach to individual patients, as the previous concern for I-124 contamination has likely been resolved. ${ }^{32}$ In addition, milk can be measured for radioactivity before being given to the child. ${ }^{33}$

Technetium-99m pertechnetate has a short half-life (6 hours) but higher background levels than radioiodine. It is the preferred agent when the patient has recently received thyroid-blocking agents (such as iodinated contrast media). Breastfeeding recommendations regarding Tc-99m pertechnetate depend on the dose administered, as it does have higher concentrations in breast milk than other radiopharmaceuticals. ${ }^{34}$ Owing to potential for differences in radiopharmaceutical production, the length of interruption recommended ranges from 12 to 24 hours, and may be as short as 4 hours for $185 \mathrm{Mbq}(5 \mathrm{mCi}){ }^{23}$ The milk expressed can be stored refrigerated and given to the infant after 10 physical half-lives, or about $\sim 60$ hours, have elapsed. ${ }^{34}$

Renal imaging. There are four radiopharmaceuticals that are commonly used in renal imaging. Technetium-99m pentetate (Tc-99m DTPA) is used to evaluate glomerular filtration rate (GFR). Technetium-99m mertiatide (Tc-99m MAG3) is used to estimate effective renal plasma flow. Technetium-99m succimer (Tc-99m DMSA) is used to evaluate the renal cortex. Technetium Tc-99m glucoheptonate allows assessment of renal perfusion, renal collecting system/ureters, and renal cortex. No interruption in breastfeeding is required for any of these agents because their free pertechnetate is negligible.

Cardiac imaging. The two most common aspects of cardiac function that may need to be evaluated in the lactating patient include evaluation of myocardial perfusion and assessment of left ventricular function.

A "stress test" is the study used for the evaluation of myocardial perfusion. Stress tests were initially obtained using thallium-201. This radionuclide has since been largely replaced by Tc-99m sestamibi and Tc-99m tetrofosmin. These newer radiopharmaceuticals are now preferred for assessing myocardial perfusion. No interruption in breastfeeding is 
required when Tc-99m sestamibi or Tc-99m tetrofosmin is used, because lower doses of these Tc-99m compounds are excreted into breast milk. ${ }^{34,35}$ The recommendations for thalium vary from a 48-hour to 3 -week interruption period. We recommend discussion with your local nuclear medicine physician regarding the approach to individual patients, and consider testing breast milk for radioactivity. ${ }^{23}$

A multigated acquisition scan (MUGA) can be used to assess left ventricular ejection fraction, and technetium-99m pertechnetate is the radionuclide used to label autologous RBCs for this test. The recommendations for MUGA depend on whether in vivo or in vitro labeling of the RBCs was performed. No breastfeeding interruption is required for in vitro labeling, which occurs outside of the patient. However, a 6-12-hour interruption is recommended for in vivo labeling, as Tc-99m pertechnetate is directly injected into the patient using this protocol. The milk expressed can be stored, refrigerated, and given to the infant after 10 physical half-lives, or $\sim 60$ hours, have elapsed. ${ }^{34}$ In breastfeeding patients, an echocardiogram should be strongly considered as an alternative to MUGA, because it is not associated with any radiation.

Ventilation-perfusion scan. A ventilation-perfusion (VQ) scan can be used to evaluate for pulmonary embolism in patients with iodinated contrast allergy or renal insufficiency. Imaging of both perfusion and ventilation is obtained. A mismatched defect in perfusion imaging can indicate the presence of a pulmonary embolism. The perfusion agent used is technetium- $99 \mathrm{~m}$ macroaggregated albumin (Tc-99m MAA). The ventilation agents include Tc-99m DTPA and xenon-133.

For Tc-99m MAA, 12-hour interruption is recommended. Although no interruption is required for the ventilation agents Tc-99m DTPA or xenon gas, a 12-hour interruption is recommended for all VQ scans because these agents are always used in conjunction with the perfusion agent Tc-99m MAA. ${ }^{34,36,37}$ During interruption, patients should express breast milk every 3-4 hours for 10-15 minutes or until minimal milk flows. The milk expressed can be stored refrigerated and given to the infant after 10 physical half-lives, or $\sim 60$ hours, have elapsed. ${ }^{34,38-40}$

It should be noted that CT angiography is the preferred imaging modality for the evaluation of suspected pulmonary embolism in all patients without contraindication to iodinated contrast. In the setting of contrast allergy or renal insufficiency (GFR <30), VQ scan can be performed with the already noted guidelines regarding interruption for Tc-99m MAA.

\section{Recommendations for Future Research}

The safety of intravenous contrast agents and commonly used radionuclides has been well studied. As new agents are introduced, further research will need to be performed.

\section{Annotated Bibliography}

For more information on radiology and nuclear medicine protocols for lactating women, please see the Supplementary Data.

\section{Supplementary Material}

Supplementary Data

\section{References}

1. Boivin G, de Korvin B, Marion J, et al. Is a breast MRI possible and indicated in case of suspicion of breast cancer during lactation? Diagn Interv Imaging 2012;93:823-827.

2. Espinosa LA, Daniel BL, Vidarsson L, et al. The lactating breast: Contrast-enhanced MR imaging of normal tissue and cancer. Radiology 2005;237:429-436.

3. Expert Panel on Breast Imaging, diFlorio-Alexander RM, Slanetz PJ, et al. ACR appropriateness criteria: Breast imaging of pregnant and lactating women. $\mathrm{J}$ Am Coll Radiol 2018;15(11S):S263-S275.

4. Helewa M, Levesque P, Provencher D, et al. Breast cancer, pregnancy, and breastfeeding. J Obstet Gynaecol Can 2002;24:164-180; quiz 181-184.

5. National Comprehensive Cancer Network Inc. NCCN Clinical Practice Guidelines in Oncology: Breast Cancer Screening and Diagnosis. 2018; Version 3.2018. Available at https://www.nccn.org/professionals/physician_gls/pdf/ breast-screening.pdf (accessed November 1, 2018).

6. Newman J. Breastfeeding and radiologic procedures. Can Fam Physician 2007;53:630-631.

7. Obenauer S, Dammert S. Palpable masses in breast during lactation. Clin Imaging 2007;31:1-5.

8. Robbins J, Jeffries D, Roubidoux M, et al. Accuracy of diagnostic mammography and breast ultrasound during pregnancy and lactation. AJR Am J Roentgenol 2011;196:716-722.

9. Sabate JM, Clotet M, Torrubia S, et al. Radiologic evaluation of breast disorders related to pregnancy and lactation. Radiographics 2007;27 Suppl 1:S101-S124.

10. Talele AC, Slanetz PJ, Edmister WB, et al. The lactating breast: MRI findings and literature review. Breast $J$ 2003;9: 237-240.

11. Vashi R, Hooley R, Butler R, et al. Breast imaging of the pregnant and lactating patient: Physiologic changes and common benign entities. AJR Am J Roentgenol 2013;200:329-336.

12. American College of Radiology. ACR Manual on Contrast Media. Administration of contrast media to women who are breast-feeding. 2018 (Version 10.3), 99-100. Available at https://www.acr.org/-/media/ACR/Files/Clinical-Resources/ Contrast_Media.pdf (accessed November 1, 2018).

13. Davis PL. Anaphylactoid reactions to the nonvascular administration of water-soluble iodinated contrast media. AJR Am J Roentgenol 2015;204:1140-1145.

14. Bettmann MA. Frequently asked questions: Iodinated contrast agents. Radiographics 2004;24 Suppl 1:S3-S10.

15. Webb JA, Thomsen HS, Morcos SK; Members of Contrast Media Safety Committee of European Society of Urogenital Radiology (ESUR). The use of iodinated and gadolinium contrast media during pregnancy and lactation. Eur Radiol 2005; 15:1234-1240.

16. Tremblay E, Therasse E, Thomassin-Naggara I, et al. Quality initiatives: Guidelines for use of medical imaging during pregnancy and lactation. Radiographics 2012;32:897-911.

17. Wang PI, Chong ST, Kielar AZ, et al. Imaging of pregnant and lactating patients: Part 1, evidence-based review and recommendations. AJR Am J Roentgenol 2012;198:778-784.

18. Tirada N, Dreizin D, Khati NJ, et al. Imaging pregnant and lactating patients. Radiographics 2015;35:1751-1765.

19. Rofsky NM, Weinreb JC, Litt AW. Quantitative analysis of gadopentetate dimeglumine excreted in breast milk. J Magn Reson Imaging 1993;3:131-132.

20. Kubik-Huch RA, Gottstein-Aalame NM, Frenzel T, et al. Gadopentetate dimeglumine excretion into human breast milk during lactation. Radiology 2000;216:555-558. 
21. Lin SP, Brown JJ. MR contrast agents: Physical and pharmacologic basics. J Magn Reson Imaging 2007;25:884-899.

22. Siegel J. Guide for Diagnostic Nuclear Medicine. Nuclear Regulatory Commission Regulation of Nuclear Medicine; 2002. Available at https://www.nrc.gov/materials/miau/miaureg-initiatives/guide_2002.pdf (accessed November 1, 2018).

23. Stabin MG, Breitz HB. Breast milk excretion of radiopharmaceuticals: Mechanisms, findings, and radiation dosimetry. J Nucl Med 2000;41:863-873.

24. International Commission on Radiological Protection, Radiation Dose to Patients from Radiopharmaceuticals. Annex D. Recommendations on breastfeeding interruptions. ICRP Publication 106, Annals of the ICRP 38:163-165, 2008.

25. Alexander EK, Pearce EN, Brent GA, et al. 2017 Guidelines of the American Thyroid Association for the diagnosis and management of thyroid disease during pregnancy and the postpartum. Thyroid 2017;27:315-389.

26. Howe DB, Beardsley M, Bakhsh S. Consolidated Guidance About Materials Licenses: Program-Specific Guidance About Medical Use Licenses. Vol. 9; 2008. Available at https://www.nrc.gov/docs/ML0734/ML073400289.pdf (accessed November 1, 2018).

27. Jamar F, Buscombe J, Chiti A, et al. EANM/SNMMI guideline for $18 \mathrm{~F}-\mathrm{FDG}$ use in inflammation and infection. J Nucl Med 2013;54:647-658.

28. Mettler F, Guiberteau M. Essentials of Nuclear Medicine Imaging. 6th ed. Philadelphia, PA: Saunders Elsevier, 2012, pp. 565-567.

29. Society of Nuclear Medicine. The SNM Procedure Guideline for General Imaging 6.0. 2010 (Version 6.0). Available at http://snmmi.files.cms-plus.com/docs/General_Imaging Version_6.0.pdf (accessed November 1, 2018).

30. Mandel SJ, Shankar LK, Benard F, et al. Superiority of iodine-123 compared with iodine-131 scanning for thyroid remnants in patients with differentiated thyroid cancer. Clin Nucl Med 2001;26:6-9.

31. International Atomic Energy Agency. Radiation Protection and Safety in Medical Uses of Ionizing Radiation, IAEA Safety Standards Series No. SSG-46, IAEA, Vienna. 2018. https//www.iaea.org/publications/11102/radiation-protectionand-safety-in-medical-uses-of-ionizing-radiation (accessed April 26, 2019).

32. Drugs and Lactation Database (LactMed) [Internet]. Bethesda (MD): National Library of Medicine (US); 2006-. Sodium Iodide I 131. Updated October 31, 2018. Available at https://www.ncbi.nlm.nih.gov/books/NBK501563 (accessed April 22, 2019).

33. Romney B, Nickoloff EL, Esser PD. Excretion of radioiodine in breast milk. J Nucl Med 1989;30:124-126.

34. Leide-Svegborn S, Ahlgren L, Johansson L, et al. Excretion of radionuclides in human breast milk after nuclear medicine examinations. Biokinetic and dosimetric data and recommendations on breastfeeding interruption. Eur J Nucl Med Mol Imaging 2016;43:808-821.

35. Drugs and Lactation Database (LactMed) [Internet]. Bethesda (MD): National Library of Medicine (US); 2006-. Technetium Tc 99m Sestamibi. Updated October 31, 2018). Available at https://www.ncbi.nlm.nih.gov/books/NBK501581 (accessed April 22, 2019).

36. Howe DB, Beardsley M, Bakhsh S. Appendix U. Model Procedure for Release of Patients or Human Research Subjects Administered Radioactive Materials. NUREG1556. Consolidated guidance about materials licenses. Program-specific guidance about medical use licenses. Fi- nal report. U.S. Nuclear Regulatory Commission Office of Nuclear Material Safety and Safeguards. 2008;9, Rev. 2. Available at www.nrc.gov/reading-rm/doc-collections/nuregs/ staff/sr1556/v9/r2 (accessed April 22, 2019).

37. Mattsson S, Johansson L, Leide Svegborn S, et al. Radiation dose to patients from radiopharmaceuticals: A compendium of current information related to frequently used substances. Ann ICRP 2015;44(2 Suppl):7-321.

38. Mountford PJ, Coakley AJ. A review of the secretion of radioactivity in human breast milk: Data, quantitative analysis and recommendations. Nucl Med Commun 1989;10:15-27.

39. Early PJ, Sodee DB. Principles and Practice of Nuclear Medicine. 2nd ed. St. Louis: Mosby-Year Book, Inc., 1995, pp. $1380-1381$.

40. Administration of Radioactive Substances Advisory Committee. Notes for guidance on the clinical administration of radiopharmaceuticals and use of sealed radioactive sources. 2006;25-27. Available at www.arsac.org.uk (accessed April 22, 2019).

$\mathrm{ABM}$ protocols expire 5 years from the date of publication. Content of this protocol is up-to-date at the time of publication. Evidence-based revisions are made within 5 years or sooner if there are significant changes in the evidence.

Katrina B. Mitchell, MD, lead author Margaret M. Fleming, MD, MSc Philip O. Anderson, PharmD, FASHP Jamie G. Giesbrandt, MD

The Academy of Breastfeeding Medicine Protocol Committee:

Michal Young, MD, Chairperson Larry Noble, MD, Translations Chairperson Sarah Reece-Stremtan, MD, Secretary Melissa Bartick, MD, MSc Sarah Calhoun, MD

Sarah Dodd, MD

Megan Elliott-Rudder, PhD, MBBS

Laura Rachel Kair, MD

Susan Lappin, MD

Ilse Larson, $M D$

Ruth A. Lawrence, MD Yvonne LeFort, $M D$

Kathleen A. Marinelli, MD Nicole Marshall, MD

Catherine Murak, MD Eliza Myers, $M D$

Adora Okogbule-Wonodi, MD Audrey Roberts, MD

Casey Rosen-Carole, MD, MPH, MSEd

Susan Rothenberg, MD

Tricia Schmidt, MD

Tomoko Seo, MD

Natasha Sriraman, $M D, M P H$

Elizabeth K. Stehel, MD

Rose St. Fleur, MD

Nancy Wight, MD

Lori Winter, MD, MPH

For correspondence: abm@bfmed.org 